\section{Diálogos entre Serviço Social e Educação Popular: reflexão baseada em uma experiência científico-popular}

\author{
Dialogues between social work and \\ popular education: thinking based on a \\ popular-scientific experience
}

\section{Lucia Conde de Oliveira*} Sâmia Barros Vieira** Hevelanya Albano de Sousa*** Maria Sônia Lima Nogueira**** Célia Maria Machado de Brito***** Isabelle Rocha Fernandes******

* Assistente social, doutora em saúde coletiva, professora adjunta de Serviço Social da Universidade Estadual do Ceará-UECE — Fortaleza, Brasil. E-mail: conde.lucia@gmail.com.

** Assistente social, residente em saúde da família e comunidade de Fortaleza, Brasil. E-mail: sa_mia vieira@hotmail.com.

*** Assistente social; pós-graduanda em Serviço Social, Políticas Públicas e Direitos Sociais.E-mail: hevelanya@hotmail.com.

**** Assistente social, mestrado em Políticas Públicas e Sociedade. Secretaria Municipal de Assistência Social de Fortaleza,Brasil.E-mail: politicaspublicasuece@hotmail.com.

***** Doutora em Educação Brasileira, professora adjunta de pedagogia da Universidade Estadual do Ceará, Fortaleza-Brasil.E-mail: celiambrito@hotmail.com.

****** Estudante de serviços social da Universidade Estadual do Ceará, Fortaleza-Brasil.E-mail: isabelle. nandes@gmail.com.
Resumo: O artigo apresenta uma reflexão acerca da contribuição da educação popular para a formação e atuação dos assistentes sociais. Possui como cenário uma experiência de extensão universitária popular de caráter emancipatório e libertador no campo da saúde. Ressalta-se a importância da utilização da educação popular no fortalecimento das dimensões teórico-metodológica, ético-política e técnico-operativa do exercício profissional do serviço social, com vistas a reafirmar o saber popular, respeitar a autonomia dos sujeitos e construir com eles alternativas de intervenção.

Palavras-chave: Serviço Social. Educação popular. Extensão universitária.

\begin{abstract}
The article focuses on the contribution of popular education in the preparation and practice of the social workers. An experiment was carried out with popular university extension about the popular, emancipatory and liberating character in the healthcare field. It highlights the importance of using popular education to strengthen the theoric-methodological, ethical-political and thecno-operative dimensions of their professional practice, aiming to reassert popular wisdom, respect their autonomy and build alternative intervention with them.
\end{abstract}

Keywords: Social Work. Popular education. University extension

\section{Introdução}

Este artigo é um convite à reflexão sobre a contribuição da educação popular para a formação e atuação dos assistentes sociais e para o fortalecimento do seu projeto ético-político profissional. Nosso interesse por essa temática adveio da nossa experiência como participantes do Projeto de Extensão Liga de Saúde da Família 
(LSF), ${ }^{1}$ e posteriormente do Programa de Educação pelo Trabalho para a Saúde (PET-Saúde) da Universidade Estadual do Ceará (Uece). Tal projeto surge da necessidade de reorientar a formação profissional e o processo de ensino-aprendizagem nos cursos da área da saúde, no intuito de atender aos princípios do Sistema Único Saúde (SUS), priorizando a formação de profissionais mais sintonizados com as necessidades do SUS.

O projeto elaborado pela Uece em parceria com o Sistema Municipal Saúde Escola de Fortaleza buscou ainda construir espaços interdisciplinares e multiprofissionais fundamentados nos princípios da educação popular e da educação permanente em saúde (Barreto et al., 2012). Assim, a estratégia baseada em metodologias participativas tem propiciado uma reflexão crítica sobre as diversas formas de intervenção e dinâmica do processo de trabalho em saúde, a fim de sensibilizar estudantes, professores e profissionais de saúde para a atenção primária. Nesta ótica, sobressai a importância da Estratégia Saúde da Família (ESF) como uma proposta inovadora de mudança do modelo de atenção à saúde no Brasil.

Ademais, o projeto possibilitou nossa inserção nos centros de saúde da família (CSF) e na comunidade, o que nos propiciou uma percepção ampliada e interdisciplinar do contexto social e dos processos de saúde e doença da população. Essa

1. Esse projeto foi contemplado com o prêmio Sérgio Arouca de Gestão Participativa no SUS $-3^{\mathrm{a}}$ edição, 2009, na categoria Experiência Exitosa. experiência nos fez vislumbrar os desafios de uma extensão universitária pautada na interdisciplinaridade e nos princípios de uma educação transformadora, superando a velha noção assistencialista tradicionalmente desenvolvida. Uma extensão não como transmissão de um saber superior, elitizado e desprovido de respeito aos saberes e práticas populares, mas como a promoção de práticas vinculadas aos interesses e necessidades da população mais pobre.

Desse modo, a aproximação com a perspectiva comunitária e interdisciplinar orientada pela educação popular nos forneceu subsídios para a compreensão e o redimensionamento da prática, quer com a população, quer na própria docência como dimensão social da formação humana. Esta realidade nos levou a refletir ainda sobre sua relação com o Serviço Social e sua convergência com o desenvolvimento de um projeto ético-político profissional norteado por uma postura crítica e transformadora. Para tanto, identificamos nas categorias interdisciplinaridade e educação popular possibilidades de questionar um modelo de extensão e de valores predominantes na universidade que, historicamente, têm fortalecido uma dimensão hierárquica do conhecimento, trazendo reflexos na formação e, consequentemente, nos serviços prestados à coletividade. Nesse prisma, o acesso ao referencial teórico de Paulo Freire (1996, 2001, 2006, 2008) nos fez refletir sobre o sentido da extensão universitária e, assim, nos aproximou, cada vez mais, das bases de um projeto profissional comprometido 
com a mudança e com uma pedagogia de base popular transformadora. Desta forma, assumimos posturas contra-hegemônicas no fazer da extensão.

Para melhor compreensão do leitor organizamos este texto da seguinte forma: inicialmente abordamos a contribuição teórica de Paulo Freire para a extensão universitária; em seguida apresentamos a relação dialética entre o projeto ético-político do Serviço Social e a educação popular e, finalmente discutimos a experiência do PET-Saúde, enfocando as contribuições do Serviço Social, principalmente no tocante à sua perspectiva socioeducativa.

\section{Paulo Freire e os pressupostos de uma extensão universitária de base popular}

Refletir sobre uma extensão de caráter social, político e problematizador remete-nos à pedagogia dialógica de Paulo Freire e à sua proposta de extensão universitária gestada na organização dos movimentos sociais populares e grupos comunitários, do final dos anos 1950 e início dos 1960 no Nordeste do Brasil. Pensador comprometido com a vida, com a educação e com a existência do educando, o nome de Paulo Freire (1921-97) está associado à luta pela educação dos oprimidos, e suas ideias contribuíram para um repensar das práticas educativas, já que o cerne da sua educação é o processo de libertação dos oprimidos (Brito, 2010).

Freire destacou-se no Brasil e, depois, no mundo por ter contribuído para um decisivo momento de redefinição da universidade e da extensão universitária, sobretudo ao liderar um Movimento de Cultura Popular (MCP) em Recife-PE nos anos 1950 a 1960. Voltado para a produção da arte, cultura, música junto à população mais pobre, o MCP caracterizou-se como um movimento de extensão universitária de caráter inovador, sistemático, transformador e dialógico, constituindo-se lócus nascedouro do método de Paulo Freire e das suas teorias, conhecidas mundialmente.

Como educador, foi o primeiro a sistematizar teoricamente a experiência, fundamentando no humanismo ${ }^{2}$ os princípios de uma proposta educativa que, em sua denominação, incorporou o adjetivo popular, com claro posicionamento político, a serviço dos interesses dos oprimidos da sociedade (Stotz, 2007). Caso não tivesse sido abortado pelo regime militar, com a prisão de Paulo Freire, proibição da publicação das suas ideias no Brasil e exílio, esse movimento poderia ter se constituído um forte momento de redefinição da universidade e da extensão universitária bem como a construção de um projeto para superação do analfabetismo no Brasil. Suas ideias de extensão cultural propostas no Plano de Governo de Veloso Alvorado, no Peru, demonstraram sua propriedade, como método emancipador, constituindo-se

2. "O humanismo é um compromisso radical com o homem concreto. Compromisso que se orienta no sentido de transformação de qualquer situação objetiva na qual o homem concreto esteja sendo impedido de ser mais" (Freire, 2008, p. 22). 
contraponto e fundamento dos conceitos e práticas de extensão universitária, no Brasil, nos anos subsequentes à ditadura militar (Brito, 2010).

Ao criticar o extensionismo agrícola, de orientação americana, antidialógica e mecanicista, Freire (2006) fundamentou uma concepção de extensão, não como ato de invasão cultural, mas como uma ação cultural norteada por um processo educativo fundado na prática da liberdade. Para Freire, é necessário compreender o outro como sujeito histórico, cultural e portador de valores e de cultura que precisam ser respeitados.

Em seu ensaio sobre o modelo de extensão agrícola, Paulo Freire (2006) discute desde a teoria filosófica do conhecimento até os elementos que embasam a prática autoritária e domesticadora. Para isso, apresenta a noção do diálogo e da comunicação em contraposição à extensão como instrumento da invasão e da conquista.

Em sua ótica, o conhecimento na dimensão humana exige uma presença curiosa do sujeito em face do mundo, o que requer uma reflexão crítica sobre $o$ ato de conhecer e uma ação transformadora. Com essa finalidade, educador e educando precisam assumir o papel de sujeitos cognoscentes mediatizados pelo objeto que buscam conhecer, num processo de criação e recriação do aprendido. A extensão na perspectiva freireana jamais separa o ensino dos conteúdos do desvelamento da realidade. Para tanto, é indispensável estimular a vivência do diálogo e a presença organizada das classes sociais populares na luta em favor da democratização da sociedade, no sentido da superação das injustiças sociais. Dessa forma, favorece o protagonismo dos grupos populares.

Ao acreditar que sem diálogo não há compromisso com a mudança, pois mediante o diálogo é que educador e educando vão em busca da palavra, em sua dupla dimensão, Freire retomou a essência do serviço de extensão universitária, resgatou sua feição política e social e sua dimensão interdisciplinar como elo fundamental do pensar e do fazer universitários (Brito, 2010).

Desse modo, recupera a unidade nas funções de ensino-pesquisa-extensão, garantindo uma integralização curricular na universidade. Ao mesmo tempo possibilita uma intervenção qualificada nas demandas sociais identificadas, permitindo mudanças substanciais na prática universitária, retroalimentando-a, e direcionando-a no sentido de uma verdadeira práxis social. Assim, sua concepção contribui efetivamente para uma revisão da política de extensão universitária, resgatando sua função mediadora no processo de mudança das condições sociais de dominação e produção de uma nova consciência social.

A partir dele, evidenciou-se a necessidade de valorização e troca de saberes com grupos populares, sobremodo ao recuperar e dimensionar as funções sociais e de articulação da universidade com a sociedade. Dessa forma, além de quebrar a verticalidade coisificadora onde um ator é sujeito e o outro objeto, típico da pedagogia conservadora tradicional, ele pensa a extensão como uma relação na 
qual todos podem ser sujeitos atuantes que agem e pensam criticamente, pois na conscientização, ou por meio dela, o homem adquire uma consciência e um compromisso histórico.

Logo, a extensão na perspectiva freireana traz a força motriz do reconhecimento e da valorização do outro como sujeito histórico-cultural, da horizontalidade dos saberes, do reconhecimento e respeito à diversidade cultural, revestindo-se, portanto, de um caráter dialogal e do compromisso com a transformação social.

Por conseguinte, o movimento de extensão de base freireana conseguiu influenciar o ideário da extensão universitária no Brasil, embora não se possa afirmar ser este referencial predominante nas práticas extensionistas das universidades públicas, na atualidade. Exemplo disso é o flagrante desrespeito às premissas acordadas por ocasião da instalação do Fórum Nacional de Pró-Reitores de Extensão das Universidades Públicas Brasileiras em 1987, quando afinaram ideias e pressupostos conceituais de natureza progressista, como mostra o texto a seguir:

O compromisso social da Universidade na busca da solução dos problemas mais urgentes da maioria da população; a indissociabilidade entre as atividades de Ensino, Extensão e Pesquisa; o caráter interdisciplinar da ação extensionista; a necessidade de institucionalização da Extensão no nível das instituições e no nível do MEC; o reconhecimento do saber popular e a consideração da importância da troca entre este e o saber acadêmico; e a necessidade de financiamento da Extensão como responsabilidade governamental.

(Nogueira, 2001, p. 67)

Conforme salienta Nogueira, pode-se identificar forte influência das ideias de Paulo Freire em propostas da extensão nas universidades públicas brasileiras, construídas no período em que a sociedade vivenciava o processo de democratização. Estas aparecem revestidas de uma dimensão democrática, problematizadora, resultante de um processo dialético, em que a teoria dialoga com a prática de forma interdisciplinar, possibilitando a troca de saberes popular e acadêmico, numa visão ampla e integrada da realidade social.

Entretanto, não podemos afirmar ser essa conceituação, de base expressivamente freireana, uma prática dominante no conjunto das experiências de extensão das universidades públicas. Na verdade, a normatização da educação superior, apesar de algumas mudanças nas concepções pedagógicas no interior das universidades, ainda não conseguiu desmontar o paradigma cientificista que toma a universidade como polo exclusivo de produção de saberes, no qual a extensão é concebida como mecanismo de acessibilidade ao conhecimento gerado nas instituições na forma de cursos, numa via de mão única de saber.

Isso reafirma o contraditório discurso veiculado, o que possibilita afirmar que, a despeito do avanço conceitual verificado no Plano Nacional de Extensão Universitária, orientado na perspectiva da Universidade Cidadã, as universidades públicas em geral, e do nosso caso específico, a 
Uece, ainda está longe de assumir a contento suas funções acadêmicas, sociais e de articuladora do saber e do fazer da universidade com a sociedade. Portanto, é mister uma redefinição dos conceitos e das práticas de extensão voltadas para uma efetiva mobilização da comunidade acadêmica na direção de uma práxis integrada, interdisciplinar, sintonizada com o conhecimento novo e com a realidade e demandas das populações mais pobres, construindo, assim, um novo pensar e fazer universitários.

Como integrantes dessa universidade e ao vivenciar práticas de extensão inovadoras e interdisciplinares, trazemos para o debate as contribuições do projeto ético-político do Serviço Social para essa experiência.

\section{Convergências entre o projeto ético-político do Serviço Social e a educação popular}

O Serviço Social constituiu-se a partir de determinado contexto histórico, ou seja, a profíssão constrói-se como "um produto sócio-histórico, adquire sentido e inteligibilidade na dinâmica societária da qual é parte e expressão" (Iamamoto, 2007, p. 26). O assistente social é um trabalhador assalariado participante da divisão sociotécnica do trabalho no seio da contradição do sistema capitalista, de modo especial na era dos monopólios. Assim, a profissão surge diretamente vinculada à sociedade capitalista, isto é, na contradição entre capital e trabalho, que se reflete na relação entre quem paga (Estado, iniciativa privada ou terceiro setor) e quem demanda seus serviços (classe trabalhadora).

Nesse contexto, durante muitos anos a atividade do assistente social destinou-se, fundamentalmente, a auxiliar e subsidiar o exercício de controle social e difundir a ideologia da classe dominante junto à classe trabalhadora, facilitando sua manipulação e dominação (Iamamoto e Carvalho, 1988).

A crítica a esse Serviço Social tradicional nasce com o movimento de reconceituação, na década de 1960, na América Latina. Contudo, no Brasil a implantação da ditadura militar provocou a emergência da modernização conservadora ${ }^{3}$ e na segunda metade da década de 1970, "quando a ditadura começa a experimentar a sua erosão, que se fazem sentir no Brasil as ressonâncias das tendências que, na Reconceituação, apontavam para uma crítica radical do tradicionalismo [...]" (Netto, 2005 , p. 17). Essa crítica se fundamenta no marxismo e nos anos 1980 avança na construção do Projeto Profissional de Ruptura.

Na década de 1980, este se consolida e torna-se hegemônico no discurso teórico-metodológico da profissão (Silva et al., 2007). Firma-se o projeto profissional que defende uma prática profissional comprometida com os interesses da classe

3. Única exceção a essa tendência, nesse período, é a experiência desenvolvida, entre 1972 e 1975, pela Universidade Católica de Belo Horizonte, conhecida como método BH (Netto, 2005). 
trabalhadora, convertendo o assistente social em um aliado das lutas populares.

Silva et al. (2007) aponta alguns eixos estratégicos para viabilizar, metodológica e operativamente, o projeto profissional de ruptura, que tiveram maior expressividade nos anos de 1980. São eles: a formação de alianças com as classes populares, a educação popular e a investigação-ação. E no final de 1980 e nos anos de 1990, a redefinição da prática da assistência. Entre estes, ressaltamos a prática da educação popular, porquanto esta "vem reafirmar a importância de uma leitura crítica da realidade na qual o assistente social e os sujeitos com os quais trabalha estão inseridos, e destaca a construção do conhecimento como tarefa coletiva" (Silva et al., 2007, p.178-79).

Assim, a ação educativa e desveladora da realidade baseada na ação-reflexão junto às classes populares contribui para a organização e participação popular. Tal ação requer um claro direcionamento político da transformação social e se desenvolve mediante um contexto reflexivo-crítico sobre as relações sociais, colocando, pois, a educação popular, a educação libertadora como algo fundamental nesse processo (Silva et al., 2007).

Estudo recente de Machado (2012, p. 154) faz uma reflexão crítica sobre a educação popular e o Serviço Social, dando conta da ausência desse debate na academia. Todavia, concordamos com a autora quando afirma que: "isso não significa que não haja assistentes sociais atuando com a educação popular e/ou debatendo-a em outras áreas, como saúde e educação por exemplo". E é justamente, para continuar o debate reavivado por Machado que trazemos a público essa experiência como um convite a novas reflexões.

Identificamos, por conseguinte, que o projeto profissional de ruptura vincula-se a um processo de construção de uma nova ordem societária sem exploração de classe, etnia e gênero. Desse modo, fortalece seu compromisso político com a classe trabalhadora, aspecto expresso claramente no Código de Ética de 1986 e reafirmado no Código de 1993.

Ao defender os interesses dessa classe, ao buscar fundamentação teórica para compreender a realidade da sociedade capitalista, o Serviço Social produz novos conhecimentos e tenta dar novas respostas às demandas sugeridas pela questão social em suas múltiplas expressões. Nesta perspectiva, como afirma Netto $(1999$, p. 4), "os projetos profissionais apresentam a autoimagem de uma profissão, elegem os valores que a legitimam socialmente, delimitam e priorizam seus objetivos e funções [...]”. Com isso, observamos o projeto profissional do Serviço Social comprometido com a construção de uma nova ordem social, com outra sociedade mais justa e igualitária, o que o coloca sintonizado com a pedagogia freireana, de valorização do oprimido.

Ainda segundo Netto (1999), na transição dos anos 1980 para os 1990, o projeto ético-político do Serviço Social brasileiro se configurou em sua estrutura básica no sentido de que, ao manter seus eixos fundamentais, tem a flexibilidade para incorporar novas questões e enfrentar desafios emergentes. 
$\mathrm{O}$ autor reflete sobre o projeto ético-político no tocante a alguns dos seus princípios e especialmente no reconhecimento da liberdade como valor central, conforme destacado:

[...] a liberdade concebida historicamente, como possibilidade de escolher entre alternativas concretas; daí um compromisso com a autonomia, a emancipação e a plena expansão dos indivíduos sociais.[...] A partir dessas escolhas que o fundam, tal projeto afirma a defesa intransigente dos direitos humanos e a recusa do arbítrio e do preconceito, contemplando positivamente o pluralismo - tanto na sociedade como no exercício profissional. (Netto, 1999, p.104)

Como podemos perceber, pelo exposto, o projeto ético-político do Serviço Social instrumentaliza o assistente social a trabalhar questões relacionadas à cidadania, à emancipação e à autonomia dos sujeitos individuais e coletivos, conceitos defendidos pela educação popular. Dessa forma, esses elementos que sintonizam o assistente social com a proposta freireana via projeto ético-político, explicita a opção pela classe trabalhadora, com vistas à garantia dos seus direitos civis, sociais e políticos, nos impõem a responsabilidade de valorizar o outro, seu saber, sua cultura. Como se depreende, o método proposto por Paulo Freire oferece fundamentação técnico-operativa para a intervenção do assistente social, seja na esfera da execução ou da gestão.

Assim, o Código de Ética do assistente social ressalta a importância da dimensão política do seu projeto. Demonstra, pois, ser a favor da equidade e da justiça social no tocante à universalização do acesso aos programas e políticas sociais.

E mais, busca o fortalecimento da cidadania, por assim dizer, indicando que os princípios constantes no Código de Ética estão em sintonia com os princípios da educação popular quando destacam a liberdade como valor ético central e a necessária autonomia dos sujeitos como uma das suas expressões. Como também a articulação com os segmentos de outras categorias profissionais que partilhem de propostas similares e, notadamente, com os movimentos que se solidarizam com a luta geral dos trabalhadores. Nesse aspecto, nos identificamos com esse referencial como participantes do Projeto Liga/PET-Saúde quando procuramos essa articulação com os movimentos populares existentes nas áreas de intervenção do projeto.

Segundo Nicolau (2004), o Serviço Social, ao ser configurado como profissão com caráter de intervenção no social, deve atentar para não correr o risco de a formação acadêmica tornar-se abstrata perante o processo histórico de contínua construção. Assim, o profissional precisa procurar desvelar, por aproximações sucessivas, o processo de transformações sociais que se vão operando no contexto social. O autor levanta a possibilidade de existir certa dicotomia e conflito entre a formação - atomizada, idealizada ou abstrata - e o fazer profissional - repetitivo, fragmentado ou apenas instrumentalizado.

De acordo com Yazbek (2009, p. 135), a "atuação da profissão na divisão social 
do trabalho se modifica e sofre redefinições com as mudanças dos contornos da questão social". Contudo, essa atuação se insere nos processo de reprodução social das classes subalternas, necessitando, portanto, apreender as mediações para compreender a relação dessas classes com o Estado e as instituições. Para tanto, requer profissionais capazes de formular, avaliar e recriar propostas no nível das políticas sociais e interpretá-las como espaços contraditórios. Atendem os interesses de controle do capital, mas também representam o atendimento de necessidades dos trabalhadores. Desse modo, ação profissional exige conhecimento, criticidade e credibilidade no protagonismo dos sujeitos sociais.

No exercício profissional, o assistente social encontra possibilidades de intervir propondo um espaço de autonomia dos sujeitos sociais mediante o cotidiano por eles vivenciado. Para tanto, o profissional deve portar uma capacidade teórico-metodológica, técnico-operativa e ético-política traduzida na bagagem da sua formação acadêmica complementada pelas experiências adquiridas no campo de intervenção.

Assim, a instrumentalidade do Serviço Social abre a possibilidade de estabelecer relação com a metodologia problematizadora de Paulo Freire, especialmente por se constituir como uma profissão que interfere "na reprodução material e social da força de trabalho, tanto por meio das ações materiais como das ações de cunho sociopolítico e ideocultural" (Mioto, 2009, p. 498).
É nesse sentido que Abreu (2002), ao aprofundar essa perspectiva com base no pensamento de Gramsci, afirma que as atividades desenvolvidas pelos assistentes sociais têm uma "função pedagógica", cujo princípio educativo está condicionado pelos vínculos que a profissão estabelece com as classes sociais. A autora denomina como uma "pedagogia emancipatória" voltada a contribuir para subverter a maneira de pensar e de agir dos homens como totalidade histórica e assim subverter a ordem intelectual e moral estabelecida no capitalismo.

Mioto (2009) estrutura as ações socioeducativas em dois pilares: um relacionado à socialização de informações e outro referente ao processo reflexivo desenvolvido na relação estabelecida entre usuários e profissionais. Destacamos o processo reflexivo, pois este tem como objetivo a formação da consciência crítica.

Esse objetivo somente se realiza à medida que são criadas as condições para que usuários elaborem, de forma consciente $\mathrm{e}$ crítica sua própria concepção de mundo. Ou seja, que se façam sujeitos do processo de construção da sua história dos serviços e das Instituições e da história da sua sociedade. (Mioto, 2009, p. 503)

Também, conforme enfatiza Lima (2006), as bases do processo reflexivo estão no diálogo e na problematização, categorias presentes na educação popular. Um diálogo cujo ponto de partida teórico e prático é a própria realidade, a realidade concreta histórica como um todo, a demonstrar que o diálogo não é 
um meio de persuasão ou estratégia de convencimento e manipulação, mas sim uma relação de intercâmbio de mensagens, de relações de poder e de uma visão geral do processo social.

Nesse prisma, o método da educação popular nos propicia além do fortalecimento teórico-metodológico e ético-político, um instrumental técnico-operativo, o qual nos coloca como ponto de partida a valorização do saber popular, mediante o respeito à autonomia dos sujeitos e construção com eles de alternativas de intervenção. Afinal, é do projeto de vida do usuário que estamos falando. Ele é o protagonista. Nada mais natural que seu saber e seus interesses estejam no centro das discussões e sejam respeitados nas intervenções, sobretudo ao se tratar de saúde.

\section{A experiência do PET-Saúde e a participação do Serviço Social}

O Projeto de Extensão Liga de Saúde da Família foi uma parceria entre a Secretaria Municipal de Saúde de Fortaleza e a Universidade Federal do Ceará (UFC) e a Uece. Seu objetivo geral era possibilitar um processo de ensino-aprendizagem aos estudantes e docentes dos cursos de graduação da área da saúde, mediado pela realidade social vivenciada pela população e pelo contexto das unidades básicas de saúde da família.

Como relatamos, a experiência do LSF motivou-nos a concorrer ao edital do PET-Saúde em 2009, que passou a incluir, além das atividades de extensão até então desenvolvidas, o ensino e a pesquisa, fortalecendo, assim, o papel da universidade na sua relação com a sociedade. A partir de 2010, passamos a contar com noventa estudantes dos cursos de Educação Física, Enfermagem, Medicina, Medicina Veterinária, Nutrição, Psicologia e Serviço Social. Tínhamos ainda uma coordenadora, três tutoras, alguns professores colaboradores e dezoito preceptores — profissionais da estratégia saúde da família das unidades onde o programa era desenvolvido.

Esse programa é uma parceria entre o Ministério da Saúde (MS) e o Ministério da Educação (MEC) e faz parte de uma política nacional do MS para reorientação da formação profissional em saúde (PRÓ-Saúde), que procura implementar um dos objetivos do SUS estabelecido pela Lei n. 8.080/1990, qual seja, ordenar a formação dos recursos humanos na área da saúde.

Para formatação do projeto pautamo-nos nos princípios que regem o SUS, bem como nos elementos conceituais e operacionais da educação permanente, da educação popular em saúde, do método da roda (Campos, 2000) e do trabalho em equipe interdisciplinar. Essas abordagens nos proporcionaram ferramentas potentes para o desenvolvimento do projeto de forma participativa.

O método de cogestão de coletivos sistematizado por Campos (2000), também conhecido como método da roda, traz como princípios a democratização das 
instituições e o fortalecimento dos sujeitos. Para construir esse método, Gastão Wagner Campos bebe em várias fontes, tais como: o materialismo histórico e dialético, a psicanálise, a análise institucional, a educação popular, entre outras.

$\mathrm{Na}$ operacionalização do projeto, acordamos com as equipes de trabalho as diretrizes e uma linha de ação. Para isso, definimos papéis e responsabilidades e discutimos sobre os temas prioritários, traçando um plano de atuação. O processo de formação dos estudantes procurou fomentar nos futuros profissionais o compromisso com os oprimidos num processo contínuo de ação-reflexão-ação. Segundo Paulo Freire (2008, p. 16), para que o profissional seja comprometido "é preciso que seja capaz de, estando no mundo, saber-se nele. Saber que, se a forma pela qual está no mundo condiciona a sua consciência deste estar, é capaz, sem dúvida, de ter consciência desta consciência condicionada". O exercício desse compromisso se fez na medida em que os sujeitos se inseriam nos espaços comunitários e participavam das decisões e encaminhamentos do projeto. Assim como Freire, Campos (2000) também propõe a necessidade do compromisso do profissional. A proposta dos círculos de cultura de Freire é ressignificada na roda, onde os sujeitos analisam os processos vivenciados e participam da tomada de decisões; organizam o projeto; fazem estudos tanto nas rodas de equipes - com conteúdos referentes ao campo comum da saúde coletiva, quanto nas rodas de categoria - quando estudam os conteúdos específicos de cada categoria profissional envolvida no projeto. Nas rodas também era trabalhada a dimensão terapêutica, quando cuidávamos do grupo, formando vínculos, problematizando os conflitos surgidos no cotidiano. Além das rodas de equipe e de categoria, realizávamos as rodas ampliadas, onde cada grupo de trinta estudantes, com seus respectivos preceptores e a tutora, planejavam atividades, socializavam os trabalhos das equipes, promoviam oficinas de aprendizagem de diferentes temas relevantes para o projeto e avaliavam o processo de forma sistemática. Era, pois, um processo permanente de ação-reflexão-ação que constitui a práxis humana.

Nesses encontros, o grupo foi se apropriando do referencial teórico de Paulo Freire, conhecendo as experiências de educação popular em Saúde, dialogando com outros projetos da Secretaria Municipal de Saúde de Fortaleza, como o Cirandas da Vida e a Residência Multiprofissional em Saúde da Família e Comunidade (RMSFC).

Com a articulação de diferentes metodologias participativas, fortaleceu-se o trabalho desenvolvido, facilitou-se o processo de aprendizagem. A vivência dialógica no contexto das classes populares possibilitou uma troca de saberes e experiências, a qual contribuiu para formação de um conhecimento novo e uma nova concepção de mundo. Ao se apropriarem da metodologia da educação popular, os profissionais de Saúde, os professores e estudantes, passavam a construir uma relação diferente com as classes populares. Reconheciam, portanto, a necessidade 
de partir do saber popular e contribuir para problematizar os diferentes saberes - científico e popular - favorecendo assim formas coletivas de aprendizagem. É nesse sentido que afirmamos com Freire e Nogueira (2011, p. 86): “[...] educação popular e mudança andam juntas. Essa educação renovada transforma não apenas os métodos de educar. Transforma as pessoas que são educadas em uma sociedade em transformação".

Nessa ótica, o científico e o popular se complementam num esforço de superação da descontinuidade e da fragmentação da história e do saber das classes dominadas. Esse esforço de superação de uma consciência ingênua ou mágica para alcançar uma consciência crítica não é só das classes populares, mas também dos próprios estudantes.

Nesse contexto, vislumbramos o potencial da atuação do Serviço Social junto às ações desenvolvidas no projeto, que vai desde a valorização de metodologias participativas, primando por espaços democráticos, até o compromisso ético-político com as classes populares. Identificamos também a contribuição do Serviço Social nas atividades de educação em saúde na perspectiva de trazer uma abordagem crítica e problematizadora da realidade; nas ações de fortalecimento da participação popular e controle social nos conselhos locais de saúde e de articulação da intersetorialidade, uma vez que a formação em Serviço Social propõe desenvolver, entre outras habilidades, as capacidades de iniciativa, de articulação, de negociação e de mobilização.
Orientado para propiciar um conhecimento aprofundado do contexto político e cultural onde se insere a ação educativa, de modo a propiciar reflexões questionadoras sobre esse contexto, o método de base freireana tem se constituído não apenas um espaço de reflexão, mas um caminho viabilizador de uma intervenção na perspectiva da transformação social. Revestindo-se de um conteúdo conscientizador, tal método, ao considerar o saber das classes populares como ponto de partida do processo pedagógico, ensejou aos estudantes o aproveitamento da experiência adquirida com os movimentos sociais e organizações populares na luta pela saúde, pelo trabalho, nas questões de gênero, entre outras. Isto significa reconhecer e admitir que o outro saber é tão válido quanto o saber técnico-científico.

A problematização, pedra de toque do método preconizado por Freire, tem se feito presente na abordagem relacional, representando etapa fundamental no processo. Com base nos questionamentos e nas problematizações ocorridas, durante as rodas e no trabalho com a comunidade, os sujeitos se apropriam da realidade e desvelam representações e questões intrínsecas ao processo saúde-doença, bem como os questionamentos e a compreensão acerca da realidade, com vistas a desmistificá-la.

Como o grupo de estudantes era multiprofissional, bastante heterogêneo, de semestres diferentes e conteúdos curriculares diversos, iniciamos as atividades do projeto com oficinas problematizando alguns conhecimentos básicos, tais como: histórico da política de saúde no Brasil; 
discussão sobre atenção primária em saúde e a estratégia de saúde da família; educação popular; participação popular e controle social; observação participante e as metodologias participativas. Alguns desses conteúdos eram mediados pelos participantes dos movimentos sociais atuantes nos territórios dos centros de saúde da família onde trabalharíamos.

Num segundo momento, procedemos à inserção das equipes multiprofissionais na comunidade e nos CSF. Esta foi facilitada pelo grupo de professores que contou com o apoio dos agentes comunitários de saúde. Durante essa inserção, a observação participante foi a técnica utilizada para a coleta de informações registradas em diário de campo. A inserção comunitária foi subsidiada pela territorialização, que se constitui como o processo de reconhecimento do território de atuação. Assim, os estudantes entrevistaram líderes comunitários, a fim de resgatar a história de luta da comunidade, visitaram os principais equipamentos sociais e identificaram limites e potencialidades de cada espaço. Posteriormente, todos os dados foram sistematizados e problematizados com os profissionais e a comunidade para a construção do planejamento participativo, momento no qual foram definidas coletivamente as prioridades de atuação e os projetos de pesquisa.

A sistematização dos estudos teve como referências teóricas os conhecimentos do campo comum da saúde coletiva e os conteúdos específicos de cada categoria profissional envolvida no projeto.

Inseridos nos territórios da estratégia saúde da família, os estudantes colabora- ram com as equipes de saúde nas ações desenvolvidas por elas, sempre interessados em levar a metodologia da educação popular para essas intervenções. Apesar de existir desde a década de 1970, o movimento de educação popular em saúde (Vasconcelos, 2001) é contra-hegemônico, ocorrendo por iniciativas individuais de profissionais comprometidos com as classes populares e que tiveram conhecimento de como operar com o método. Contudo, nos CSF onde as equipes de estudantes passaram a atuar, não identificamos profissionais com habilidades na educação popular.

De modo geral, a formação na área da saúde ainda é muito tecnicista, com iniciativas recentes de reformulações dos currículos que procuram trazer conteúdos da saúde coletiva, da vigilância à saúde, dos determinantes sociais do processo saúde-doença, atenção primária em saúde, entre outros. Segundo depoimentos dos estudantes participantes do projeto, este significou uma oportunidade ímpar de adquirir esses conhecimentos e vivenciar uma experiência interdisciplinar de grande relevância para sua formação profissional.

A maioria dos estudantes de Serviço Social demonstrou conhecimentos e habilidades para o desenvolvimento do projeto. A despeito de não terem uma formação específica para a saúde, a teoria social crítica que embasa a formação permite ao estudante adquirir um conhecimento sobre a constituição econômica, social, política e cultural da sociedade brasileira favorecendo dessa forma a compreensão sobre a realidade onde irá atuar, possibilitando 
construir uma visão ampliada dos determinantes sociais da saúde. Os conteúdos da formação, mesmo para os estudantes ainda nos primeiros semestres, já contribuíam para uma concepção crítica da realidade requerida pela atuação no projeto.

Ainda como podemos destacar, esses conteúdos da formação do assistente social orientaram docentes e discentes nas discussões sobre a construção do projeto de pesquisa referente à participação popular na estratégia saúde da família e mediaram as problematizações com profissionais e usuários na construção dos projetos participativos para atuação das equipes nas comunidades. Entre os projetos desenvolvidos, enfatizamos o da formação de uma rede intersetorial em um dos territórios acompanhados pelo PET-Saúde (Vieira, 2011), e os projetos que priorizaram o estímulo à organização, mobilização e participação das classes populares e o fortalecimento do controle social por meio de ações voltadas para a revitalização dos conselhos locais de saúde dos CSF integrantes do PET-Saúde. Nas ações de educação em saúde, os estudantes de Serviço Social desempenharam papel relevante ao propor para discussão nos grupos os direitos dos usuários do SUS, a violência contra crianças e adolescentes, entre outros temas determinantes e/ou condicionantes do processo saúde-doença.

Nessa perspectiva, o assistente social em sua atuação profissional de caráter sociopolítico pode contribuir para a quebra de modelos e paradigmas predominantes no setor saúde, que se restringe ao indivíduo e sua condição de saúde, sem proble- matizar aspectos sociais que interferem no processo saúde-doença. Assim, reforça uma compreensão crítico-dialética entre o individual e o social.

Isso significa fortalecer uma atuação não limitada ao que Stotz (2007, p. 56) denomina de preventismo, mas focada na educação popular e saúde que considera o contexto social das classes populares, e como ponto de partida seu saber, reconhecendo-o "tão válido, no âmbito do diálogo, quanto o saber técnico-científico". E, ainda: preocupando-se em compartilhar e explorar as crenças e os valores dos serviços a respeito de certa informação sobre saúde, bem como discutir suas implicações, fortalecendo a iniciativa das comunidades com vistas a buscar soluções para os problemas de saúde na reflexão sobre a complexidade da dialética entre o individual e o coletivo.

\section{Considerações finais}

A produção deste texto permitiu-nos reconstruir nossa experiência de extensão universitária emancipatória, criticá-la, identificando o aprendizado proporcionado ao conjunto dos estudantes, professores, profissionais de saúde e comunidade. Experiências inovadoras encontram muitos obstáculos, não só pela novidade, pois cotidianamente precisávamos reinventar estratégias de trabalho e descobrir formas de superação dos desafios, tais como: conciliar horários de estudantes de cursos e turmas diferentes — as rodas 
aconteciam aos sábados — lidar com os conflitos teóricos e ideológicos que surgiam; buscar apoio e nem sempre encontrar, nas instâncias superiores das instituições envolvidas - universidade e Secretaria Municipal de Saúde.

Pensar questões relacionadas à política de saúde por meio de atividades de extensão na universidade, de modo especial à atenção básica, nos possibilitou identificar que a atuação do Serviço Social na saúde e a educação popular apresentam-se numa relação dialética. Conforme entendemos, essa relação entre Serviço Social e educação popular deve ser estimulada desde a formação acadêmica. Percebemos, no entanto, que esse tema é pouco abordado no Serviço Social, ${ }^{4}$ e há pouca produção teórica, a despeito de existir uma aproximação política e ideológica da formação e atuação profissionais com as discussões presentes no âmbito da educação popular.

É importante ressaltar que o projeto ético-político do Serviço Social tem sua hegemonia na formação acadêmica. Contudo, precisa ampliar essa hegemonia no exercício profissional, exigindo, assim, maior comprometimento na sua consolidação, que pode ser potencializado pela apropriação da metodologia educação popular como um instrumental técnico-operativo potente para trabalhar com as classes populares.

Aprendemos durante nossa formação que as profissões se criam a partir das

4. Alguns estudantes de serviço social da Uece têm a possibilidade de estudar a educação popular em disciplina optativa ofertada pelo curso de Pedagogia. necessidades sociais, se desenvolvem e se reproduzem na medida da sua utilidade social. Nesse prisma, segundo compreendemos, a prática profissional do assistente social não está firmada sobre uma única necessidade, mas em várias necessidades, e seu objeto são as múltiplas expressões da questão social que se nos apresentam no cotidiano profissional.

Para que esta prática se concretize com um efeito útil na vida de seus demandantes oriundos das classes populares, é mister ser crítica e participativa, além de promover um desvelamento da realidade. Uma realidade que desafia os profissionais a decifrá-la a todo o momento. Contudo, esse desvelamento pode produzir mudanças na medida em que essa ação se desenvolva de forma dialógica com os trabalhadores.

É, então, em meio às mudanças sociais verificadas na contemporaneidade que $o$ Serviço Social traz marcante contribuição com seu saber específico para impulsionar uma reflexão política com os segmentos populacionais oprimidos, na busca da garantia da sua autonomia. Desse modo, eles poderão reconhecer seus direitos e deveres rumo ao exercício de sua cidadania plena.

Ainda segundo compreendemos, um assistente social comprometido com a transformação da realidade pode se valer dos pressupostos da educação popular para desempenhar seu papel político de educador social. Deve, contudo, para além de propor, construir projetos focados na mesma intenção transformadora da educação idealizada por Paulo Freire, esclarecendo direitos, desnudando desigualdades e injustiças da sociedade capitalista, que 
valoriza cada vez mais o individualismo em detrimento dos valores de igualdade $\mathrm{e}$ solidariedade.

Finalmente, na nossa ótica só teremos profissionais propositivos que, efetivamente, priorizarão em sua prática profissional a classe trabalhadora, conforme orientação do Código de Ética do assistente social, se forem formados na perspectiva social crítica e dialética, num claro confronto do arcabouço teórico das disciplinas de sala de aula com a vida pulsante do cotidiano das classes subalternas. Daí também a importância do ensino fora dos muros acadêmicos, nos espaços miúdos dos territórios comunitários, espaço privilegiado para os estudantes nos campos de estágios e especialmente na extensão universitária, local de onde falamos.

Recebido em 1/10/2012

Aprovado em 11/3/2013

\section{Referências bibliográficas}

ABREU, M. M. Serviço Social e a organização da cultura: perfis pedagógicos da prática profissional. São Paulo: Cortez, 2002.

BARRETO, I. C. H. C. et al. Gestão participativa no SUS e a integração ensino, serviço e comunidade: a experiência da Liga de Saúde da Família, Fortaleza, CE. Saúde e Sociedade, São Paulo, v. 21, supl. 1, maio 2012. Disponível em: <http://dx.doi.org/10.1590/S0104$-12902012000500007>$. Acesso em: 25 ago. 2012.
BRITO, C. M. M. O Programa Nacional de Educação em Áreas de Reforma Agrária (Pronera): recuperando aspectos de uma relação de parceria entre Universidade, Governo e Movimentos Sociais do Campo. In: CONGRESSO DA ASSOCIACIÓN LATINOAMERICANA DE SOCIOLOGIA RURAL, 8., Anais..., 2010, Pernambuco. Disponível em: <http://www. alasru.org/wp-content/uploads/2011/07/ GT6-C\%C3\%A9lia-Maria-Machado-de-Brito. pdf $>$. Acesso em: 23 jan. 2012.

CAMPOS, G. W. S. Um método para análise e cogestão de coletivos: a constituição do sujeito, a produção de valor de uso e a democracia em instituições - o método da roda. São Paulo: Hucitec, 2000.

FREIRE, P. Pedagogia da autonomia: saberes necessários a prática educativa. Rio de Janeiro: Paz e Terra, 1996.

Conscientização: teoria e prática da libertação. São Paulo: Centauro, 2001.

. Extensão ou comunicação? 13. ed. Rio de Janeiro: Paz e Terra, 2006.

Educação e mudança. 31. ed. Rio de Janeiro: Paz e Terra, 2008.

; NOGUEIRA, A. Que fazer: teoria e prática em educação popular. 11. ed. Petrópolis: Vozes, 2011.

IAMAMOTO, M. V. Serviço Social em tempo de capital fetiche: capital financeiro, trabalho e questão social. São Paulo: Cortez, 2007.

; CARVALHO, R. Relações Sociais e Serviço Social no Brasil: esboço de uma interpretação histórico-teórico-metodológica. 6. ed. São Paulo: Cortez; Lima: Celats, 1988.

LIMA, T. C. S. As ações sócio-educativas e o projeto ético político do Serviço Social: tendências da produção bibliográfica. Dissertação (Mestrado) - Universidade Federal de Santa Catarina, Santa Catarina, 2006. 
MACHADO, A. M. B. Serviço Social e educação popular: diálogos possíveis a partir de uma perspectiva crítica. Serviço Social \& Sociedade, São Paulo, n. 109, 2012.

MIOTO, R. C. Orientação e acompanhamento social a indivíduos, grupos e famílias. Serviço Social: direitos sociais e competências profissionais. Brasília: CFESS/Abepss, 2009.

NETTO, J. P. A construção do projeto ético-político do Serviço Social frente à crise contemporânea. Capacitação em Serviço Social e Politica Social. Módulo I. Brasília: CFESS/ Abepss/Cead/UnB, 1999.

O movimento de Reconceituação 40 anos depois. Serviço Social \& Sociedade, São Paulo, ano XXVI, n. 84, 2005.

NICOLAU, M. C. C. Formação e fazer profissional do assistente social: trabalho e representações sociais. Serviço Social \& Sociedade, São Paulo, edição especial, ano XXV, n. 79, p. 82-17, 2004.

NOGUEIRA, M. D. P. Extensão universitária no Brasil: uma revisão conceitual. In: FARIA, D. S. (Org.). Construção conceitual da extensão na América Latina. Brasília: Ed. UnB, 2001.
STOTZ, E. Enfoques sobre educação popular e saúde. Brasil. Ministério da Saúde, Secretaria de Gestão Estratégica e Participativa. Cadernos de Educação Popular e Saúde, Brasília, Ministério da Saúde, 2007.

SILVA, M. O. S. et al. Esforço de construção de um projeto profissional a partir da ruptura. In: SILVA, M. O. S. (Coord.). O Serviço Social e o popular: resgate teórico-metodológico do projeto profissional de ruptura. 4. ed. São Paulo: Cortez, 2007.

VASCONCELOS, E. M. Redefinindo as práticas de saúde a partir da educação popular nos serviços de saúde. In: . A saúde nas palavras e nos gestos. São Paulo: Hucitec, 2001. p. 11-19.

VIEIRA, S. B. Tecendo redes, construindo laços, caminhando a lentos passos: um processo de ação-reflexão junto a rede intersetorial do Vila União. Monografia (Graduação em Serviço Social) - Universidade Estadual do Ceará, Fortaleza, 2011.

YAZBEK, M. C. O significado sócio-histórico da profissão. In: CFESS/ABESS (Org.). Serviço Social: direitos sociais e competências profissionais. Brasília: CFESS/Abepss, 2009. 